\title{
Challenges of Learning English in Australia towards Students Coming from Selected Southeast Asian Countries: Vietnam, Thailand and Indonesia
}

\author{
Cao Thanh Nguyen (Corresponding author) \\ Faculty of Education, La Trobe University, Victoria 3086, Australia \\ Postal address: 17 Burton St., Lalor, Victoria 3075, Australia \\ Tel: 61-401-248-847 E-mail: thanhthu7580@yahoo.com
}

\begin{abstract}
The paper will explore the challenges students from selected South East Asian countries (Vietnam, Thailand and Indonesia) face while studying English in Australia before entering into Australian University courses. These students must contend not only with different styles of teaching and learning, but also with the challenge of adapting to a new culture. The study was conducted at one of the largest language institutions in Melbourne (affiliated with a major University), and the results collected draw on the English learning experiences of nine students (three Vietnamese, three Thai and three Indonesian) and two language teachers. Semi-structured interviews were adopted as the primary data collection method, and this allowed the major problems that these students experience while studying English for University entry to be identified. The findings of this paper include reasons why Vietnamese, Thai and Indonesian students find it difficult to study in Australia, and possible solutions for overcoming these difficulties and improving the English proficiency of students from these countries.
\end{abstract}

Keywords: English learning, Challenges, Cultural adaption

\section{Introduction}

In recent times, a number of Asian students, particularly South East Asian have been to Australia for study. The issues Asian students face while studying in Australian institutions have attracted attention from a number of scholars, for instance Herger (1992), Denise \& Simone (1997), Ballard \& Clanchy (1997), Biggs (1997), Biggs (2003), Wong (2004), Exley (2005), Edwards \& Hui (2007). All of whom have examined the learning achievements of Asian students, and also investigated the challenges students face when learning English at the beginning.

Quite a lot of Asian students spend time at Language Centres in Australia before entering universities. At the beginning, the issue of shifting from traditional backgrounds to a new environment in an English speaking country is not an easy task. Furthermore, Asian students usually bring along their learning styles from their mother countries when they go overseas to study (Ballard \& Clanchy, 1997; Biggs, 1997, 2003). Thus, the initial difficulties that arise in learning English are unavoidable and result from both new teaching and learning styles immersion into a different culture.

In this paper, I have narrowed the focus to examine the challenges that students from selected South East Asian countries (Vietnam, Thailand and Indonesia) face when learning English. The reasons for not including students from all South East Asian countries are various. Firstly, there are not many students from Laos, Cambodia, East Timor or the Philippines studying in Australia. Secondly, English proficiency of Malaysian and Singaporean students is very high, so they often go straight into Australian universities without having to go through English preparation courses.

In addition, the numbers of Thai, Vietnamese and Indonesian students undertaking academic and English courses in Australian institutions are significant. According to Department of Foreign Affairs and Trade (2010) Australia is one of the most popular destinations for Thais studying abroad, with about one third doing so in Australia - Australia registered over 22,000 Thai student enrolments in 2008. Moreover, Australia is a leading study destination for Vietnamese students, with approximately 20,000 enrolments in Australian education institutions and an estimated number of 14,000 students undertaking study or training in Australian run off shore courses in Vietnam. Equivalently, there are about 16,000 Indonesian enrolments in Australian institutions. However, studies investigating difficulties facing Thai, Vietnamese and Indonesian students while learning English in Australia are rare. So for this reason, I carried out this study using students from these countries to fill this research gap. The study was conducted at one of the biggest language centres in Melbourne while students were studying English to meet the language requirements before entering university. The purpose of this study is to explore difficulties those students have learning English before going to their main courses, and how they overcome those difficulties. 


\section{The learning styles of Asian and South East Asian students through perceptions of Western scholars}

Scholars claim that while acknowledging that the situation is improving, Asian students in general, and South East Asian students in particular are still passive and rote learners. Those characteristics are obviously exposed when these students study overseas (Nieto, 1992; Park, 2000; Ballard \& Clanchy, 1997; Biggs, 2003; Exley, 2005). Park (2000) states that because reticence and humility are highly valued in Asian cultures, Southeast Asian students tend to be passive and nonverbal in class. Those students can be afraid of losing face in front of other classmates if they answer incorrectly, thus they do not want to show their ideas and they are not confident in participating in group discussions in ESL classrooms (Vang, 1999; Lewis, 1996). Park (2000) adds that student learning is "accomplished through rote memorization and teachers' lectures" (247). Consistent with Clara's views, Vang (1999), Biggs (2003) and Lewis \& Luangpraseut (1989) all assume that generally, in Southeast Asian classrooms, experiential and interactive learning activities are rare, and most of the time students listen to a teacher's lecture and take notes.

Moreover, Asian students are less autonomous, and they dislike 'ambiguity', 'uncertainty', or 'fuzziness' (Rao, 2001). Rao shows that, the reasons leading to these problems are due to 'teacher-centered' and learning a 'closure-oriented learning mode'. There are many lecturers from Western universities who report difficulties in teaching international Asian students. These difficulties were summarized by Biggs (2003) as follows:

'They rote learn and lack critical thinking skills;

'They are passive; they won't talk in class'

'They appear to focus excessively on the method of assessment'

'They don't understand what plagiarism means'

'They stick together...won't mix with locals'

'They do not easily adjust to local conditions'

'They tend to look on lecturers as close to gods'

'Progressive western teaching methods won't work with Asian'

(Biggs, 2003: 125-131)

Most of these above comments about Asian students' learning styles are quite appropriate. However, I believe a critical aspect of the learning process has been neglected in these observations. Students studying abroad must contend with not only a different style of teaching and learning but also with the challenges of adapting to a new culture, and this cannot be done overnight.

\section{Influences of cultural differences towards Asian students}

International students Asian students included often bring with them overseas cultural differences. Nieto (1992) assumes that cultural differences in learning may be particularly evident in three areas: learning styles, interactional or communication styles, and language differences. Following Sonia's work, Ballard \& Clanchy (1997) state that "different cultural traditions do embody different attitudes to knowledge" (9). They report the expression of one Thai student as a demonstration for the above statement:

When I am in class and the professor asks questions and we have to discuss, I never say anything. Often I think of answers, but I cannot express my ideas well, so I wait for someone else to speak for me. I have never asked a question either. The other students ask many questions and even argue with the professor. I can never do that, because I do not think that is the right behaviour. I do not want to become like Australian students.

(2nd Thai undergraduate)

This example from a Thai student is true for almost all the Asian students whose cultures and traditions lead them to see their teachers as superiors, and thus questioning or arguing with teachers rarely happens. Asian students often feel shocked and embarrassed when they see the "disrespectful" behaviours of Australian students towards their teachers when they first come to Australian universities. Example of behaviour that seems to be "disrespectful" includes calling a lecturer by his/her first name, remaining seated when the teacher enters the room, or walking through a door ahead of a tutor (Ballard \& Clanchy, 1997).

In Vietnam where strong influences of Confucian ideology still remain, every Vietnamese student knows by heart proverbs and sayings about the role and position of the teacher, such as:

Vua, thay, cha ay ba ngoi

Kinh tho nhu mot tre oi ghi long

The King, the teacher and the father are at different positions; but children remember that they should venerate them 
equally as one unified person.

(Phuoc, 1975, cited in Ellis, 1995)

Or

Cha me sinh con thay cho cuoc song

My parents give me birth but my teacher made a man of me

Or

Khong thay do may lam nen

You would do nothing without a teacher

Or

Muon sang phai bac cau kieu

Muon con hay chu phai yeu lay thay

To get over a river, you must need a bridge

To become a good student, you have to admire the teacher

At school, there are several slogans attached to the class wall which praise the teacher's credit in graduating, for instance:

Nhat tu vi su, ban tu vi su

Whoever teaches me a letter should be my teacher

The super hierarchy of the teacher has been embedded on Vietnamese students' thoughts. As a result, when they go overseas to study, they are not confident in communicating or interacting with teachers. Like other Asian students, Vietnamese students hardly express their own opinions in the class, especially in front of teachers. Thus, the distant interaction between teachers and students in the cultures of origin is one of the reasons affecting student's learning styles and also communication styles in Western classrooms.

\section{Method}

The participants in this study were students and teachers at a Language Centre attached to a university in Northern Melbourne. The participants include: two English teachers (TC1, TC2), both of whom have over five year experience in teaching English for international students. Additionally, the study included nine students from three countries: Thailand (3: T1,T2,T3), Vietnam (3: V1,V2,V3) and Indonesia (3:I1,I2,I3). All of these students are studying English at this institution. These students have been learning English at the centre for between two and four months.

Semi-structured interviews were adopted as a method for data collection. The interviews were carried out in Vietnamese language for three Vietnamese students and English for other participants. Interviews were conducted individually based on leading questions, and were audio recorded. The audio was then transcribed into English (except for the three Vietnamese whose were transcribed into Vietnamese and translated into English).

The role of the researcher in this study was evidently exposed in terms of the relationship with participants. The researcher is a student advisor for Asian students, so he has maintained a warm and open communication with students and teachers daily and regularly. This aspect seems to be an advantage of the investigator during conducting interviews. Specifically, both interviewer and interviewees felt comfortably and confidently, as they knew each other for a while. The participants were willing to share their experiences without strain and embarrassment. During interviews such an open environment outweighed the limitation of the language barrier such as different accents or difficulty of pronunciation between the researcher and respondents.

The data was analysed manually based on the purpose of this study. The information gathered from participants was supplemented from my own experiences as a learner at a language institution before, and was categorized into main themes as follows 'English learning experiences in the countries of origin'; 'challenges in learning English in Australia'; 'reasons leading to problems in learning English'; and 'possible solutions to improve English and expectations'.

\section{Findings and discussions}

\subsection{English learning experiences in the countries of origin}

All students acknowledged that English lectures in their countries focused a lot on grammar, and other skills were not adequately taught. They reported that from primary school to high school, or even at university, teachers often 
taught them grammar and vocabulary which was taken from textbooks. I1 revealed that "teachers far too often taught grammar, and we were also directed to learn grammar to pass exams. Most of the tests or exams were mainly on grammar and reading". Responding to this point, T1 said "even when teaching us writing, teachers still corrected and gave feedback in terms of grammatical evaluating such as the right order of subject, object or using tenses in each sentence". They all recognised that, at that time, they were learning English theoretically and not pragmatically.

Others skills like speaking, pronunciation, listening or writing were also taught but not efficiently, as asserted by participants. V1 reported that normally there was only about an hour per week for practicing speaking in his high school. In this lesson, all students repeated together following the teacher's model. Further to this point, TC1 assumed that almost all English teachers in those countries were not English native people, so their pronunciation might not be good. As a result, teachers might try to avoid teaching speaking skill to students. Moreover, according to all the Thai participants, when they learnt to write in English, teachers only taught them how to write by sentences with teachers rarely instructing them how to write in long paragraphs or how to express their own opinions in their writing.

With regards, student-teacher interaction, all Vietnamese, Thai and Indonesian students stated that there was a distance between teachers and students, both inside and outside classroom. All Vietnamese respondents consistently reported that, English was taught like other subjects in their high school. In classrooms, teachers worked mostly by themselves, and students listened and wrote in silence without interrupting teachers' work. I1 and 2 added that sometimes they did not agree with teachers in regards to some matters, but they were afraid that if they strongly showed their own voice, teachers might dislike them. Consequently, the gap between teachers and students evidently hindered students' communication skills which are crucially needed in English learning and teaching.

The reflections and experiences of the student participants are useful in accessing the reality of learning and teaching English in selected Southeast Asian countries. With such approaches teaching and learning English, it is hard for students to learn English effectively or competently. Furthermore, recognition of the problems students face when learning English in Southeast Asian countries would help language teachers to develop feasible strategies to assist English learning in Australia.

\subsection{Challenges of learning English in Australia}

According to all participants, the common problems of Vietnamese, Thai and Indonesian students are pronunciation, speaking and plagiarism in writing. Both teachers stated that these cohorts of students have problems when they pronounce English words, especially with consonant classes and word ending like s, sh, t, d, x, g or j. TC2 revealed that "if they do not pronounce words properly they cannot hear them properly, because listening and speaking closely go together". When students speak, they often forget the word ending, and they drop them off. As T1, V2 and 12 expressed to teachers or friends, they forgot all the rules of pronunciation in extended utterances.

All of the respondents admitted that the rule of plagiarism in writing in their countries is not as strict as it is in English. In their countries, there is no advanced technique to check plagiarism of writing like the computer program 'turnitin'. In the first few weeks in language classes in Australia, those students felt puzzled with how to quote and paraphrase and also how to avoid plagiarism in academic writing. They all expressed that learning how to support their own ideas with the ideas from others in writing is extremely difficult.

Beside these common problems, students coming from each country also showed different difficulties in learning English. The Thai students are challenged by writing. Both TC1 and 2 said that Thai students maintain their traditional styles in their writing. These teachers went on to describe how Thai students did not show their critical thinking in writing. This problem is also evident for Indonesian students. I1, T1 and 2 all reported that if they wrote in sentences, it was not a problem, but it was challenging when they were required to write in a paragraph or an essay format. Based on comments of teachers and through student's expressions, Vietnamese students do not have difficulties in this skill, but they struggle with listening, while Thai and Indonesian students are better in this area. Three Vietnamese students showed their reports from the last few terms, they got high marks in most of the skills, but very low marks in their listening tests. TC1 and 2 asserted that too many Vietnamese students repeat levels due to low marks in listening, even though they may have high overall results.

As reflected in these findings, Thai, Vietnamese and Indonesian students experience different problems in learning English, but they all have common problems in the areas of pronunciation and plagiarism in writing. The finding of common challenges of Southeast Asian students in general and those from above selected countries in particular could help language teachers to recognise and also to efficiently address those problems. It is worth noting that almost students studying in language programs in Australia are international students, so the identification, recognition and distinguishing of common problems of students coming from different cultures are crucial. If teachers and administrators in the language centres understand and are able to recognise strengths and weaknesses of 
students from different areas such as Southeast Asia, East Asia, South America, and Middle East they may be able to adopt strategies for each group, making teaching and learning English much more productive.

\section{Reasons leading to difficulties in learning English}

\subsection{Different linguistic structures}

All teachers and students agreed that there were no strict rules for pronunciation in Thai, Vietnamese and Indonesian languages. In those languages, when speaking, people do not need to be aware of pronunciation. TC1 and 2 commented that, when students spoke their mother languages, they did not need to care about stressing the word, word ending or consonant classes. Thus, they are unfamiliar with their tongue movement, and now it is very hard to change that habit. TC1 admitted that "for me, speaking Vietnamese is so difficult, because I keep putting my tongue in a wrong place". To demonstrate that different linguistic affects speaking, TC2 explained that, students coming from South America did not have problem with speaking or listening, because the structure of their language was quite close to English. Moreover, in Thai, Vietnamese and Indonesian languages, grammatical structures were also different from English in some areas. For example, there was no past, present or future tenses in their languages, and the position of adjective and noun was opposite to English.

According to the participants' responses, different linguistic trait is one of the reasons leading to difficulties for Southeast Asian students when learning English, especially towards pronunciation. It is not totally appropriate to defend those students for their weakness of pronunciation due to linguistic variety. Nevertheless, it is worth noting that some aspects like different tongue movement or different rules of pronunciation or intonation can negatively affect pronunciation in English.

\subsection{Difficulties in adapting with new culture, language teaching and learning styles}

Both TC1 and 2 assumed that language learning style is one of the representations of culture. Therefore, Southeast Asian students still kept their traditional characteristics when studying overseas, and this was not easy to be changed overnight. Following comments of these teachers, giving personal opinions was quite difficult to Thai and Indonesian students, and they were so polite in behaving and communicating with other people, especially with teachers. Their cultures taught them to avoid arguments with others, and to try to be in harmony with each other. All students acknowledged that in their current language class, they were often grouped together in the same nationality, and they were not confident when presenting ideas individually. T1 reported that whenever she spoke English, it reminded her of the accent of Thai teachers when they taught her how to speak English. The expressions of teachers are so consistent with student's that those characteristics have been rooted and embedded in students' thought and after a period of time - in students' educational and cultural experiences.

The characteristics of cultural influences on English learning of Southeast Asian students can be seen as an explanation for complaints of Australian teachers when they teach Asian students. The complaints about learning styles of Asian students, such as 'quietness', 'rote learning', 'passiveness' or 'lack of critical thinking', have been referred in the literature review. However, to a certain degree, those characteristics do not mean that Southeast Asian students are not learning well. It should be further noted that learning style are one part of the cultural factors. Hence, when Western teachers work with international students in general and Southeast Asian students in particular, they firstly should understand the characteristics of different cultures as well as find out problems of those students' learning styles.

\section{Possible solutions and expectations}

\subsection{From students}

Both teachers agreed in the interviews that to effectively improve English, students needed to recognise their weaknesses and be more independent in learning. According to teacher's explanations, in Australia, they expect students to take ownership of their learning. TC1 stressed that recognising problems was one of the most important thing to enhance ability of learning English. She went on to emphasise that "in listening class, I often asked students to pick up the mistakes by themselves, because if they could not find the mistakes, they could not correct them". TC2 added that students needed to say directly to us 'these are my problems'.

Regarding students themselves, all of them agreed that they needed to practice more to improve their English. T1 said that he needed to have more speaking practices with friends from different nationalities. Moreover, watching TV, listening to radio and doing more reading were also good ways, he expressed. Another Thai student revealed an interesting point: "when I read, I often read loudly, so that I can find out if there is something wrong with my pronunciation".

As consistently reflected by respondents, to overcome challenges in learning English, students had to try their best and no one could do it on their behalf. If students needed someone to help them, they would need to reveal their problems, and let people know what their weaknesses were. Moreover, students needed to do more with independent 
learning, and learnt how to solve problems by themselves first before asking assistance from others.

\subsection{From teachers}

TC1 and 2 commented that in general, although, language teachers were on the right track, to some degree, they should do more to address problems in learning English of Southeast Asian students. TC2 said that teachers should understand not only the language difficulty of students in their class but also the culture issues. She gave an instance: in each classroom, there were normally, 4 or 5 different cultures, and each culture had different issues. Thus, teachers needed to understand more about the characteristics of each culture such as problem in giving opinion, politeness or being hesitant in asking for help.

Most students explained they would like their teachers to spend more time correcting their mistakes. Specifically, they expected that teachers should spend more time on correcting their pronunciation: When they pronounce something wrongly, teachers should stop them, point out the mistakes and correct them straight away. Moreover, according to three Indonesian students, when teachers return the results of the tests to students, they should give students more time to analyse their mistakes. I1 complained that "teachers gave us only about two minutes to look through the results, then they took it back, and we did not have enough time to recognise the mistakes we made".

All the participants stated that understanding the characteristics of different cultures is important in supporting student's English study. Generally, when teaching English for international students, language teachers are not officially required to understand all cultural aspects. In other words, understanding all features of all cultures is less likely to be realistic in terms of professional requirements of language teachers. Nevertheless, to a certain degree, if language teachers were able to do that, it would be much more beneficial and helpful for international students in their English study.

\subsection{From language centres}

Teachers and students all agreed that the support services available for students studying English are currently quite good, but it would be better if they met the needs of students in areas like listening and pronunciation. Both teachers assumed that the language centres should send teachers to listening labs in order to assist students in terms of listening strategies. Moreover, special support classes should be run to address specific problems of students who come from collectivist societies like those of Southeast Asia. V1 and 2 in particular stressed that language centres should run activities like teaching how to give personal opinions, politeness, or skills of how to present in front of a crowd.

The suggestions of the participants who are language teachers are also worth noting. They recommended that there should be specific activities to help students to express their personal opinions or to develop and apply critical thinking. These activities are essential for Southeast Asian students. As indicated previously, students coming from collectivist context often have troubles with such skills in learning English because of cultural influences.

\section{Limitation}

From the author's perception, the limitations of this study mostly come from the methodology. As mentioned in the method section, the method adopted in this paper was semi-structured interview only, and the numbers of population involved in this paper were limited: two teachers and nine students. Hence, the gathered data may not adequately generalise for English learning of a whole number of students coming from Vietnam, Thailand and Indonesia.

Additionally, during process of interview, the interviewees who are students coming from different nationalities, they were not very competent at speaking English. This issue probable partly affected the quality of interviews, and in some degree, some information from interviews did not adequately reach the purpose of the interviewer, and some information was likely to be dropped off.

\section{Conclusion and recommendations}

This study has delivered an overview of the learning styles of Asian students in general and Southeast Asian students in particular to audiences. The reality of teaching and learning English in Vietnam, Thailand and Indonesia also has been briefly described.

This paper has explored the situation of learning English in Vietnam, Thailand and Indonesia. Through reflections of the participants, it has been determined that learning English in those countries mostly involves concentration on grammar while other skills like speaking or pronunciation were not taught adequately.

This study has discovered the challenges of Vietnamese, Thai and Indonesian students in learning English at one of the largest language centres in Australia. Even though different difficulties are shown, the common problems in learning English for students from those countries are obvious: pronunciation, speaking and plagiarism in writing.

One of the important results of this study is to discover the reasons of these above mentioned challenges. According to explanations of the respondents, different linguistic structures and difficulties in adapting to a new culture, and 
new teaching and learning styles are the main reasons.

The study has raised possible solutions to overcome challenges and expectations to enhance the effectiveness of learning English for students from Vietnam, Thailand and Indonesia. The language teachers are expected to understand more about characteristics of different cultures in classes. The suggestions refer to students in terms of enhancing ability of independent learning, and recognising problems. Another worthy point is the implication for language centres regarding diversifying learning activities to meet the needs of international students.

From an author's perspective, I have some suggestions for international students (particularly Southeast Asian students) who are undertaking English courses in Australia. Based on findings and discussions and also from my personal experiences as a student in a university preparation English course a few years ago, I recommend Southeast Asian students maximize their strengths in grammar and effectively use them in writing. As this skill is often a weakness of other international students Southeast Asian students could engage in peer study to improve their weaknesses and the weak areas of their classmates. Ultimately, though unless students adapt to the new learning environment their progress will be affected.

Arising from limitation, further studies related to this topic will be conducted in the near future and in a larger scale. In the positive perspective, such limitations will be carefully addressed. More comprehensive and adequate methods such as surveys or observations would be employed.

\section{References}

Biggs, J. B. (1997). Teaching across and within cultures: the issue of international students. In Murray-Harvey, R. \& Silins, H. C. (Eds.) Learning and Teaching in Higher Education: Advancing International Perspectives Proceedings of the Higher Education Research and Development Society of Australasia Conference, Adelaide: HERDSA, 1-22.

Biggs, J. B. (2003). Teaching for Quality Learning at. University. Buckingham: The Society for Research into Higher Education and Open University Press.

Ballard, B. \& Clanchy, J. (1997). Teaching international students. IDP, Australia.

Department of Foreign Affairs and Trade of Australia. (2010). Advancing the interests of Australia and Australians internationally.

Department of Foreign Affairs and Trade of Australia. (2009). Advancing the interests of Australia and Australians internationally.

Exley, B. (2005). Learner Characteristics of ‘Asian' EFL Students: Exceptions to the 'Norm'. Proceedings Pleasure Passion Provocation. Joint National Conference AATE - ALEA (pp. 1-16). Gold Coast, Australia

Edwards, P. \& Hui, C. Y. (2007). Asian ESL Students and Literacy Development. Multicultural Review.

Ellis, G. (1995). Teaching and Learning Styles in Vietnam: Lessons for Australian Educators. Journal of Vietnamese Studies, No 9.

Herger, J. (1992). Bridging the International Communication gap. TAFE. International, 157-161

Lewis, C. T. \& Luangpraseut, K. (1989). Handbook for teaching Lao-speaking students. Sacramento, CA: Folsom Cordova Unified School District and Southeast Asia Community Resource Center.

Lewis, R. (1996). Indonesian Students' Learning Styles. EA Journal, 14(2), 27-32.

Nieto, S. (1992). Affirming Diversity: The Sociopolitical context of Multicultural Education. New York: Longman. (ED 361 440)

Rao, Z. (2001). Matching teaching styles with learning styles in Asian contexts. The internet TESL Journal, 7(7), 111-116.

Park, C. C. (2000). Learning Style Preferences of Southeast Asian Students. Urban Education, Vol. 35, 245-268. Corwin Press.

Vang, A.T. (1999). Hmong-American Students: Challenges and Opportunities. In C.C. Park and M.M. Chi (Eds)., Asian-American Education: Prospects and Challenges. Westport, CT: Bergin and Harvey, 218-236.

Wong, K. (2004). Are the learning Styles of Asian International Students Culturally of Contextually Based? International Education Journal, Vol 4, No 4. University of South Australia.

\section{Abbreviation \\ TC1: teacher 1 \\ TC2: teacher 2}

V1: Vietnamese student 1 
V2: Vietnamese student 2

V3: Vietnamese student 3

T1: Thai student 1

T2: Thai student 2

T3: Thai student 3

I1: Indonesian student 1

I2: Indonesian student 2

I3: Indonesian student 3

\section{Appendix 1: Interview Questionnaire}

Interview questions for teachers

How long have you taught at the Language Centre?

What are the common problems of Asian students in terms of learning English?

Could you please tell me the typical problems of learning English of the students who are from:

Vietnam

Thailand

Indonesia

What are the main reasons leading to those problems?

In your opinions, what do teachers need to do further to help those students learn English effectively?

What do students need to do further to improve their English?

What should the Language Centre do to help students learn English more productively?

Do you think that the traditional learning styles in the countries of origin negatively affect the ways of learning English in Australia?

Interview questions for students

How long have you been to Australia?

How long have you learnt English in your country before coming to Australia?

What are the main differences between English teaching and learning in Australia in comparison to those in your country?

Which skills did teachers most focus on in teaching English in your country? Which one was less focused on?

Writing

Reading

Listening

Speaking

Which skills were you good at?

Which one were you not good at?

Were there any communication activities in English class in your country?

How was the teacher-student relationship in English class in your country?

What are the most difficult tasks in learning English here?

Which skills are you not good at and why? Why do you think you are not good at these skills?

Which skills are you good at?

What did you do to improve your English here?

In your opinion, what are the best ways to overcome your problems in English learning?

What do you expect teachers to do more to help you improve your English?

Do you think your learning styles in your country negatively affect the effectiveness of learning English here?

Do you think the differences of linguistic structures negatively affect your English learning? 